AMARAL, Marcelo Quevedo do. Os serviços de interesse econômico geral (sieg) no direito comunitário europeu. Revista Eletrônica Direito e Política, Programa de Pós-Graduação Stricto Sensu em Ciência Jurídica da UNIVALI, Itajaí, v.10, n.4, $3^{\circ}$ quadrimestre de 2015. Disponível em: www.univali.br/direitoepolitica - ISSN 1980-7791.

\title{
OS SERVIÇOS DE INTERESSE ECONÔMICO GERAL (SIEG) NO DIREITO COMUNITÁRIO EUROPEU
}

\author{
THE INTEREST OF GENERAL ECONOMIC SERVICES (GEIS) THE \\ EUROPEAN COMMUNITY LAW
}

\section{Marcelo Quevedo do Amaral ${ }^{1}$}

SUMÁRIO: Introdução; 1. O Processo de Integração Europeu e o Sistema de Defesa da Concorrência; 2. Os Serviços de Interesse Econômico Geral Sieg - do Direito Comunitário Europeu; 3. Serviços de Interesse Econômico Geral - Sieg - Possíveis Influências no Sistema Brasileiro; Considerações Finais; Referências das Fontes Citadas.

\section{RESUMO}

O processo de integração da Comunidade Europeia constituiu um sistema de defesa da concorrência priorizando sua função instrumental de harmonização e integração dos mercados e sistemas jurídicos dos Estadosmembros. Por decorrência, o Direito Comunitário desenvolveu a noção de serviço de interesse geral e serviço econômico de interesse geral - SIEG, justamente com a função de mediar os efeitos da liberalização econômica e da abertura à concorrência com os objetivos comunitários de proteção ao interesse geral, público e social. Assim, a experiência do Direito Comunitário, em face de inúmeras semelhanças de objetivos e condições socioeconômicas observadas em relação ao Brasil, pode ser de grande valia na constituição de novos instrumentos de prestação de políticas públicas, no aperfeiçoamento do sistema jurídico existente e, inclusive, na interpretação e resolução de questões controvertidas que envolvem o tema.

PALAVRAS-ChAVE: Direito Comunitário Europeu; Serviços de Interesse Econômico Geral; Defesa da Concorrência; Intervenção do Estado na Economia.

\footnotetext{
1 Mestrando em Direito Público pela Universidade do Vale do Rio dos Sinos (UNISINOS). Graduado em Economia pela UFRGS e em Direito pela PUC/RS. Advogado da Caixa Econômica Federal.
} 
AMARAL, Marcelo Quevedo do. Os serviços de interesse econômico geral (sieg) no direito comunitário europeu. Revista Eletrônica Direito e Política, Programa de Pós-Graduação Stricto Sensu em Ciência Jurídica da UNIVALI, Itajaí, v.10, n.4, $3^{\circ}$ quadrimestre de 2015. Disponível em: www.univali.br/direitoepolitica - ISSN 1980-7791.

\section{ABSTRACT}

The European Community's integration process constituted an antitrust system prioritizing its instrumental function of harmonization and integration of markets and legal systems of the Member States. Consequently, the Community law developed the notion of general interest and economic service of general interest - GEIS precisely with the function of mediating the effects of economic liberalization and openness to competition with the Community objectives of protecting the general interest, public and social. Thus, the experience of Community law, in the face of numerous similarities of socio-economic objectives and conditions observed in relation to Brazil, can be of great value in setting up new provision of public policy instruments, improving the existing legal system, including, the interpretation and resolution of controversial issues surrounding the topic..

KEYWORDS: European Community Law; General Economic Interest Services; Antitrust; State intervention in the economy.

\section{INTRODUÇÃO}

O presente artigo busca fazer uma prevê apresentação do processo de integração da Comunidade Europeia, tratando de temas referentes a constituição e objetivos do sistema de defesa da concorrência no Direito Comunitário. Com essas definições preliminares, se pretende sintetizar os principais elementos que compõem os conceitos de serviços de interesse geral e serviços econômicos de interesse geral no Direito Comunitário Europeu com o objetivo de discutir possíveis adequações e ensinamentos que a experiência Comunitária Europeia pode trazer a realização dos objetivos constitucionais e ao aperfeiçoamento do sistema jurídico brasileiro.

$\mathrm{Na}$ primeira parte se apresentará o processo de integração europeu sob uma perspectiva histórica e jurídica, demonstrando como a consolidação das instituições de defesa da concorrência no continente cumpriu uma função estratégica para a harmonização e convergência das economias, mercados e sistemas jurídicos nacionais, servindo de instrumento para o desenvolvimento econômico e sustentável, a proteção social, um alto grau de competitividade, bem como de outros objetivos condizentes com a 
AMARAL, Marcelo Quevedo do. Os serviços de interesse econômico geral (sieg) no direito comunitário europeu. Revista Eletrônica Direito e Política, Programa de Pós-Graduação Stricto Sensu em Ciência Jurídica da UNIVALI, Itajaí, v.10, n.4, $3^{\circ}$ quadrimestre de 2015. Disponível em: www.univali.br/direitoepolitica - ISSN 1980-7791.

coesão econômica e social e o reforço dos laços de solidariedade entre os Estados-membros.

O Tratado de Roma de 1957 (TCE) e o regulamento 17 do Conselho Europeu de 1962, com as alterações advindas do Tratado sobre a Formação da União Européia (TFCE) ${ }^{2}$, estabeleceram a estrutura legal do sistema de antitruste europeu de forma a disciplinar a concorrência entre os agentes econômicos e as políticas de incentivo dos Estados-Membros. Além da liberdade econômica e da busca da eficiência via concorrência, o Direito Comunitário busca preservar outros valores consagrados pela União Europeia, estabelecendo exceções que se expressam basicamente através dos conceitos de serviço de interesse geral e serviço econômico de interesse geral - SIEG.

O conceito se serviço de interesse geral e SIEG tem justamente o papel de compatibilizar gradualmente o conceito e o alcance dos serviços públicos em todo o continente com a formação de um mercado interno unificado e balizado pelo fundamento da livre concorrência. Portanto, a definição comunitária de serviços de interesse geral, que alberga tanto atividades de serviços não econômicos (serviços públicos essenciais como educação, segurança e justiça) quanto os serviços de interesse econômico geral (energia elétrica, transporte, saneamento, telecomunicações, etc.), é de grande valia no processo de integração de mercados. Essas noções tem a importante função de mediar os efeitos da liberalização econômica e da abertura à concorrência com os objetivos comunitários de proteção ao interesse geral, público e social, assegurando o acesso universal, a qualidade dos serviços e a modicidade dos preços, evitando a geração de desigualdades regionais, sociais e a exclusão de setores vulneráveis ao acesso a serviços considerados essenciais.

Similarmente a União Europeia, o Brasil possui uma dimensão continental com disparidades sociais e regionais que justificam a adoção de objetivos

2 O TFCE consiste no tratado de Roma após as alterações trazidas pelo Tratado de Lisboa (2007). 
AMARAL, Marcelo Quevedo do. Os serviços de interesse econômico geral (sieg) no direito comunitário europeu. Revista Eletrônica Direito e Política, Programa de Pós-Graduação Stricto Sensu em Ciência Jurídica da UNIVALI, Itajaí, v.10, n.4, $3^{\circ}$ quadrimestre de 2015. Disponível em: www.univali.br/direitoepolitica - ISSN 1980-7791.

mais amplos que a pura e simples defesa da liberdade econômica e da concorrência. Portanto, presente a importância e atualidade do tema, a título de conclusão, se realizará uma breve reflexão sobre as possíveis influências e ensinamentos que as noções de serviço de interesse geral e serviço econômico de interesse geral - SIEG - podem trazer ao sistema jurídico brasileiro.

\section{O PROCESSO DE INTEGRAÇÃO EUROPEU E O SISTEMA DE DEFESA DA CONCORRÊNCIA}

O processo de integração europeu e a consolidação das instituições de defesa da concorrência no continente, se pode afirmar, são um produto direto do pós-guerra. Os aliados ocidentais, principalmente os EUA, consideravam as características da economia alemã, fortemente cartelizada e com grandes grupos econômicos com atuação nos mais diversos setores da economia, uma das principais causas responsáveis pela ascensão do regime totalitário e, por decorrência, pelo desencadeamento do conflito armado $^{3}$. Curiosamente, conforme registra o professor LIMA:

A legislação antitruste na Europa encontra sua referência histórica na Alemanha, primeiro país a incorporá-la, de fato, no seu aparato institucional. Nesse país, a primeira lei sobre cartéis, datada de 1923, tratava do abuso do poder econômico caracterizado por ações empresariais que conflitavam com o interesse público. O objetivo da legislação, entretanto, não era o de impedir a formação dos cartéis ou a concentração econômica, que continuou ocorrendo. Até mesmo porque durante o regime nazista a existência de um grande número de cartéis e o elevado grau de concentração de capital na economia

\footnotetext{
${ }^{3}$ Os EUA também atribuíram à concentração da economia japonesa, cartelizada e formada por holdings familiares, uma das causas do envolvimento do Japão na Guerra. A economia japonesa era dominada por cartéis e holdings familiares - os Zaibastu, a exemplo dos conhecidos grupos Mitsubishi, Sumitomo, Honda, Kawasaki e Yasuda. Esses cartéis eram criados, controlados e mantidos com autorização e supervisão do estado, sendo considerados estratégicos para o crescimento econômico japonês desde a Revolução Meiji. De modo simplificado, podemos dizer que o princípio basilar desse modelo era utilizar o planejamento e a intervenção estatal para ocupar mercados, evitar perdas geradas pelo excesso competitivo e proporcionar maiores ganhos de eficiência. Em decorrência, logo após a rendição japonesa, as autoridades estadunidenses de ocupação impõem um aparato legal de defesa da concorrência no Japão.
} 
AMARAL, Marcelo Quevedo do. Os serviços de interesse econômico geral (sieg) no direito comunitário europeu. Revista Eletrônica Direito e Política, Programa de Pós-Graduação Stricto Sensu em Ciência Jurídica da UNIVALI, Itajaí, v.10, n.4, $3^{\circ}$ quadrimestre de 2015. Disponível em: www.univali.br/direitoepolitica - ISSN 1980-7791.

demonstraram-se compatíveis e adequados às necessidades do planejamento e controle inerentes ao esforço armamentista alemão. (LIMA,1998, p. 71).

Em decorrência, já no Tratado de Postdam (1945), embora o encontro seja um marco das profundas divergências das suas relações a partir de então, os aliados passam a considerar a criação de cartéis e fusões como crimes. Com isso, a adoção de um sistema de defesa da concorrência passa a integrar os temas prioritários para todos os países da Europa Ocidental, ou seja, não integrantes do bloco soviético.

Posteriormente, no Tratado de Roma de 1957, os esforços empreendidos para formação de um mercado supranacional tratam o sistema de defesa da concorrência como instrumento indispensável para o sucesso do bloco econômico. O instituto é visto como essencial para a superação das barreiras comerciais, do protecionismo nacional e do aumento da eficiência e competitividade, permitindo à formação do mercado comum.

Nesse ponto, necessário ressaltar a dimensão dos desafios envolvidos na tarefa de integração econômica num continente marcado pelas cicatrizes recentes de dois conflitos mundiais. Onde a disputa de mercados entre países com economias fortemente concentradas e identificadas com suas nações de origem é histórica. Também por esses aspectos, a preocupação em dotar o bloco de instrumentos capazes de inibir a adoção de barreiras ou comportamentos anticoncorrenciais pelos agentes econômicos passou a ser vista pelos defensores da integração como imprescindível a criação de um ambiente institucional favorável.

O processo de integração, portanto, é impulsionado tanto por motivos de ordem econômica como de ordem geopolítica (reforçar os laços de cooperação entre os Estados membros e constituir mecanismos institucionais que afastem o perigo de novo conflito).

Esse ambiente e suas condicionantes que levam muitos autores a identificar na experiência europeia a noção de "concorrência-instrumento", defendendo o caráter instrumental do sistema de defesa da concorrência Europeu para o 
AMARAL, Marcelo Quevedo do. Os serviços de interesse econômico geral (sieg) no direito comunitário europeu. Revista Eletrônica Direito e Política, Programa de Pós-Graduação Stricto Sensu em Ciência Jurídica da UNIVALI, Itajaí, v.10, n.4, $3^{\circ}$ quadrimestre de 2015. Disponível em: www.univali.br/direitoepolitica - ISSN 1980-7791.

processo de integração do continente. A criação de um sistema de defesa da concorrência não seria um valor em si mesmo (concorrência-fim) ${ }^{4}$, mas um mecanismo possibilitador da integração dos mercados e formação da Comunidade Econômica Europeia.

Com a criação do ideal de união da Europa, viu-se na concorrência efetivamente um meio para concretizar determinada política pública, de forma institucionalizada. Intensifica-se o caráter instrumental da concorrência, que passa, então, a ser tomada com um princípio cardeal a orientar o processo de interpretação/aplicação das normas antitruste.

A União Européia, tal como hoje existe, não teria sido alcançada sem a implementação de política concorrencial consistente. Assim, as normas que disciplinam a competição são utilizadas para atingir fins maiores, tendentes à implementação dos objetivos postos pelo art. $2^{\circ}$ do Tratado CE. (FORGIONI, 2004, p. 93).

A base legal do sistema de antitruste europeu encontra-se basicamente no Tratado de Roma de 1957 (TCE) e no regulamento 17 do Conselho Europeu de 1962, com as alterações advindas do Tratado sobre a Formação da União Européia $(\mathrm{TFCE})^{5}$. Além disso, a Comissão Europeia, que cumpre funções executivas e legislativas, sendo encarregada da supervisão da aplicação do tratado, e o Tribunal Europeu, que exerce função jurisdicional, sendo responsável pela harmonização das decisões das cortes nacionais, são

\footnotetext{
4 Diversamente, nos EUA vigoraria a noção de "concorrência-fim", a instituição é um valor sócio-cultural da sociedade e deve ser defendida e resguardada por si só. A sociedade estadunidense possui um singular apreço pela livre iniciativa, pelo empreendedorismo e pelo individualismo, tendo sido formada basicamente por pequenos produtores. Nesse ambiente, o sistema de monopólios e cartéis é mais facilmente identificado com privilégios inaceitáveis e ilegítimos, causando aversão social ao serem considerados uma verdadeira ameaça a funcionalidade da economia. E foi justamente o impacto das transformações advindas do acelerado processo de concentração e centralização do capital na economia estadunidense, originando vários oligopólios e monopólios via integração vertical, na segunda metade do século XIX que geraram a reação social pela limitação e controle do poder dos trustes, apontados como responsáveis não só pelo aumento de preços e bloqueio da concorrência, mas também pela prática de corrupção, suborno, inclusive de parlamentares, fraudes, entre outros.

${ }^{5}$ O TFCE consiste no tratado de Roma após as alterações trazidas pelo Tratado de Lisboa (2007).
} 
AMARAL, Marcelo Quevedo do. Os serviços de interesse econômico geral (sieg) no direito comunitário europeu. Revista Eletrônica Direito e Política, Programa de Pós-Graduação Stricto Sensu em Ciência Jurídica da UNIVALI, Itajaí, v.10, n.4, $3^{\circ}$ quadrimestre de 2015. Disponível em: www.univali.br/direitoepolitica - ISSN 1980-7791.

instituições chaves na aplicação do direito econômico europeu, criadas pelo processo de integração.

O tema está estruturado em duas partes: uma destinada às empresas e outra disciplinando as políticas de incentivo dos Estados-Membros, por exemplo, subsídios diretos, incentivos fiscais, garantias de contratação, indução de preço, etc. Tal medida justifica-se, visto ser uma necessidade da integração coibir condutas que estabeleçam distorções na concorrência entre os agentes econômicos dos estados membros. De outra forma, a própria regra estabelece exceções, como incentivo ao desenvolvimento regional, proteção ambiental, pesquisa e desenvolvimento e promoção de pequenas e médias empresas ${ }^{6}$.

O Tratado prevê dois tipos de infração à concorrência pelas empresas: as condutas de agentes econômicos consideradas anticompetitivas independentemente da sua posição de mercado (art. 101, ex-artigo 81 do TCE) e as condutas de empresas em posição dominante art. 102 (ex-artigo 82 do TCE).

As condutas incompatíveis com o mercado comum e as práticas que possam afetar o comércio entre os Estados-membros, cujo objeto ou efeito sejam a impedir, restringir ou falsear a concorrência dentro do mercado comum são vedadas pelo art. 101, sendo os acordos com as características descritas considerados nulos, na forma do seu $\S 2^{\circ}$.

No entanto, o §30 declara essas disposições inaplicáveis, as chamadas isenções, desde que as práticas negociais (acordo, ou categoria de acordos entre empresas; decisão ou categoria de decisões, de associações de empresas; e/ou qualquer prática concertada, ou categoria de práticas concertadas) contribuam para melhorar a produção ou distribuição dos produtos ou para promover o progresso técnico ou econômico econômico,

${ }^{6} \mathrm{O}$ Tratado (art. 86) proíbe medidas que privilegiem ou criem prerrogativas especiais ou direitos exclusivos as empresas públicas dos Estados-membros. 
AMARAL, Marcelo Quevedo do. Os serviços de interesse econômico geral (sieg) no direito comunitário europeu. Revista Eletrônica Direito e Política, Programa de Pós-Graduação Stricto Sensu em Ciência Jurídica da UNIVALI, Itajaí, v.10, n.4, $3^{\circ}$ quadrimestre de 2015. Disponível em: www.univali.br/direitoepolitica - ISSN 1980-7791.

contanto que aos utilizadores se reserve uma parte equitativa do lucro daí resultante, e que:

a) não imponham às empresas em causa quaisquer restrições que não sejam indispensáveis à consecução desses objetivos; e

b) Nem dêem a essas empresas a possibilidade de eliminar a concorrência relativamente a uma parte substancial dos produtos em causa.

As condutas anticompetitivas são ainda exemplificadas pela norma:

a) fixar, de forma direta ou indireta, os preços de compra ou de venda, ou quaisquer outras condições de transação;

b) limitar ou controlar a produção, a distribuição, o desenvolvimento técnico ou os investimentos;

c) repartir os mercados ou as fontes de abastecimento;

d) aplicar, relativamente a parceiros comerciais, condições desiguais no caso de prestações equivalentes, colocando-os, por este fato, em desvantagem na concorrência;

e) subordinar a celebração de contratos à aceitação, por parte dos outros contraentes, de prestações suplementares que, pela sua natureza ou de acordo com os usos comerciais, não têm ligação com o objeto desses contratos.

Já o artigo 102 (ex-artigo 82 do TCE) proíbe os abusos de posição dominante, cabendo salientar que o objeto da proibição não é a posição dominante em si, mas o uso abusivo que dela pode ser feito, com repercussões negativas no comércio entre Estados-membros.

$\mathrm{O}$ art. 102 também exemplifica as práticas que visa coibir:

a) impor, de forma direta ou indireta, preços de compra ou venda ou outras condições de transação não eqüitativas; 
AMARAL, Marcelo Quevedo do. Os serviços de interesse econômico geral (sieg) no direito comunitário europeu. Revista Eletrônica Direito e Política, Programa de Pós-Graduação Stricto Sensu em Ciência Jurídica da UNIVALI, Itajaí, v.10, n.4, $3^{\circ}$ quadrimestre de 2015. Disponível em: www.univali.br/direitoepolitica - ISSN 1980-7791.

b) limitar a produção, a distribuição ou o desenvolvimento técnico em prejuízo dos consumidores;

c) aplicar, relativamente a parceiros comerciais, condições desiguais, no caso de prestações equivalentes, colocando-os, por esse fato, em desvantagem na concorrência;

d) subordinar a celebração de contratos à aceitação, por parte dos outros contraentes, de prestações suplementares que, pela sua natureza ou de acordo com os usos comerciais, não têm ligação com o objeto desses contratos.

Importante salientar que somente às práticas que possam afetar o comércio entre os Estados-membros são objeto de regulação pela Comunidade Europeia. Caso os efeitos fiquem limitados às fronteiras do próprio estadomembro, a competência caberá aos institutos pátrios.

O Regulamento do Conselho Europeu, por sua vez, disciplina as condições para incidência do $\S 3^{\circ}$ do art. 101, com a aprovação da isenção pela Comissão Europeia. As práticas com enquadramento neste normativo devem, obrigatoriamente, ser objeto de notificação prévia à Comissão, podendo dar origem a uma aprovação individual ou em bloco.

As isenções em bloco são uma peculiaridade do sistema antitruste da Comunidade Européia. Consubstanciadas em atos regulamentares de iniciativa da Comissão, definem uma categoria de operações às quais as regras do $\S 1^{\circ}$ do art. 81 não são aplicáveis, em razão do seu enquadramento na regra do $\S 3 \circ$, estabelecendo tipos de cláusulas que podem constar dos acordos excepcionados. Dois exemplos ilustrativos de isenções em bloco são a isenção aos acordos de especialização entre pequenas e médias empresas, do início da década de 80, aplicável a acordos envolvendo parcela de mercado em parte da Comunidade não superior a $20 \%$, 
AMARAL, Marcelo Quevedo do. Os serviços de interesse econômico geral (sieg) no direito comunitário europeu. Revista Eletrônica Direito e Política, Programa de Pós-Graduação Stricto Sensu em Ciência Jurídica da UNIVALI, Itajaí, v.10, n.4, $3^{\circ}$ quadrimestre de 2015. Disponível em: www.univali.br/direitoepolitica - ISSN 1980-7791.

e a isenção a acordos de pesquisa e desenvolvimento, de $1984 .^{7}$

A comissão realizará um exame das operações notificadas, verificando a adequação à norma legal (licitude) e o atendimento as condições do $3^{\circ}$, podendo, antes de conceder a isenção, condicionar a aprovação ao cumprimento de medidas.

São tais características que permitem considerar que a noção do sistema de defesa da concorrência na Europa é realmente instrumental ${ }^{8}$, especialmente quando considerado, como destaca FORGIONI ${ }^{9}$ que os artigos específicos do antitruste constantes do Tratado da Comunidade Europeia devem ser interpretados e aplicados de acordo com os objetivos maiores lançados principalmente em seu art. 20, ou seja, "o desenvolvimento harmonioso, equilibrado e sustentável das atividades econômicas, um elevado nível de emprego e de proteção social, a igualdade entre homens e mulheres, um crescimento sustentável e não inflacionista, um alto grau de competitividade e de convergência das economias um elevado nível de proteção e de melhoria da qualidade do ambiente, o aumento do nível e da qualidade de vida, a coesão econômica e social e a solidariedade entre os Estados-membros".

E é justamente essa função instrumental que encontramos no art. 106 (exartigo 86 do TCE) que excepciona a regra da proibição de medidas dos Estados-membros que privilegiem empresas públicas. Ou seja, o Tratado da União Europeia flexibiliza a aplicação das suas regras, permitindo aos Estados-membros manter direitos e condições especiais às empresas dedicadas à exploração de atividades de interesse econômico geral ou de

\footnotetext{
7 NUSDEO, A. M. O. Defesa da Concorrência e Globalização Econômica: O Controle da Concentração de Empresas. São Paulo: Malheiros, 2002. p. 103.

8 O avanço do processo de integração tem permitido observar o deslocamento do papel do direito de defesa da concorrência. A função instrumental para o processo de integração tem dado lugar gradativamente a a consolidação de um sistema antitruste supranacional, com as mesmas características e objetivos dos sistemas nacionais tradicionais.

9 FORGIONI, P. A. Os Fundamentos do Antitruste. São Paulo: Revista dos Tribunais, 2005. p. 217.
} 
AMARAL, Marcelo Quevedo do. Os serviços de interesse econômico geral (sieg) no direito comunitário europeu. Revista Eletrônica Direito e Política, Programa de Pós-Graduação Stricto Sensu em Ciência Jurídica da UNIVALI, Itajaí, v.10, n.4, $3^{\circ}$ quadrimestre de 2015. Disponível em: www.univali.br/direitoepolitica - ISSN 1980-7791.

monopólios naturais, na medida compatível com o caráter de desenvolvimento da atividade.

\section{OS SERVIÇOS DE INTERESSE ECONÔMICO GERAL - SIEG - NO DIREITO COMUNITÁRIO EUROPEU}

O direito comunitário europeu tem utilizado como diretriz motora do processo integração a busca permanente da conciliação e harmonização gradativa entre as diversas tradições e sistemas jurídicos nacionais. E é justamente desta peculiariedade que emerge o conceito de Serviços de Interesse Econômico Geral - SIEG - no Direito Comunitário Europeu ${ }^{10}$.

À medida que os serviços públicos organizados pelos Estados-membros desfrutavam de direitos especiais ou exclusivos, a conformação do mercado comum gerava o questionamento se eles não representavam um obstáculo à liberdade de circulação de mercadorias e à liberdade de prestação de serviços. Não obstante, o Tratado tomou em consideração esses serviços públicos sob a denominação de serviços de interesse econômico geral e previu a possibilidade de que eles sejam dispensados da observação das normas de liberdades fundamentais. ${ }^{11}$

O grande desafio das autoridades comunitárias condutoras do processo de integração era compatibilizar o conceito e alcance dos serviços públicos em todo o continente com a formação de um mercado interno unificado e balizado pelo fundamento da livre concorrência. Nesse aspecto, é imprescíndivel lembrar que tradicionalmente muitos serviços considerados de interesse econômico geral eram prestados pelos Estados europeus em regime de monopólio público, a exemplo dos serviços de energia,

\footnotetext{
${ }^{10}$ O Tratado de Roma de 1957, que instituiu a Comunidade Econômica Europeia, já previu a noção de serviço de interesse econômico geral (SIEG). O art. 90, §20 do Tratado estabeleceu o SIEG sem, no entanto, trazer uma definição clara do novo instituto.

11 JAEGER JUNIOR, Augusto. Mercado comum e interno e liberdades econômicas fundamentais. Curitiba: Juruá, 2010. p. 467.
} 
AMARAL, Marcelo Quevedo do. Os serviços de interesse econômico geral (sieg) no direito comunitário europeu. Revista Eletrônica Direito e Política, Programa de Pós-Graduação Stricto Sensu em Ciência Jurídica da UNIVALI, Itajaí, v.10, n.4, $3^{\circ}$ quadrimestre de 2015. Disponível em: www.univali.br/direitoepolitica - ISSN 1980-7791.

telecomunicações, transportes e postais. Dessa forma, o processo de integração de mercados, liberalização e abertura à concorrência teve como contraponto medidas de proteção do interesse geral, público e social. O objetivo principal dessas medidas foi assegurar o acesso universal, a qualidade dos serviços e a modicidade dos preços praticados, independentemente da situação econômica, social ou geográfica, evitando a geração de desigualdades regionais, sociais e a exclusão de setores vulneráveis do acesso a serviços considerados essenciais.

Uma consideração indispensável nesse aspecto é fazer a distinçaõ entre os serviços de interesse geral dos serviços econômicos de interesse geral - SIEG. Os serviços de interesse geral são um conceito mais abrangente, um genêro que compreende serviços de natureza econômica e não econômica. Na definição de BEZERRA,

São todas aquelas atividades de serviços prestadas aos administrados, diretamente, ou por delegação a terceiros, a que os poderes públicos impõem obrigações de serviço público, por entender que estão dotados de interesse geral, operem no mercado ou fora dele, isto é, sejam comerciais ou não. ${ }^{12}$

Portanto, os serviços de interesse geral consideram, além das atividades econômicas também as "não econômicas" que, a princípio, não interferem na liberdade concorrencial do mercado. Em essência essas atividades "não econômicas" compreendem as chamadas funções realengas do Estado, ou seja, as funções básicas que manifestam seu exercício de soberania, como segurança pública, assistência social e justiça.

O Tratado sobre o Funcionamento da União Européia (TFCE), em seção dedicada as regras aplicáveis às empresas, dentro do capítulo que disciplina as regras de concorrência, estabelece que "as empresas encarregadas da gestão de serviços de interesse económico geral - SIEG - ou que tenham a

\footnotetext{
12 BEZERRA, Helga Maria Sabóia. As transformações da noção de serviço público na União Européia: o serviço de interesse geral do Tratado de Lisboa. Direito, Estado e Sociedade n.32 p. 104 a 133 jan/jun 2008. p. 120.
} 
AMARAL, Marcelo Quevedo do. Os serviços de interesse econômico geral (sieg) no direito comunitário europeu. Revista Eletrônica Direito e Política, Programa de Pós-Graduação Stricto Sensu em Ciência Jurídica da UNIVALI, Itajaí, v.10, n.4, $3^{0}$ quadrimestre de 2015. Disponível em: www.univali.br/direitoepolitica - ISSN 1980-7791.

natureza de monopólio fiscal ficam submetidas ao disposto nos Tratados, designadamente às regras de concorrência, na medida em que a aplicação destas regras não constitua obstáculo ao cumprimento, de direito ou de fato, da missão particular que Ihes foi confiada". Pode-se notar já nesse ponto a força do princípio da subsidiariedade que orienta o processo de integração europeu, segundo o qual a ação comunitária só se justifica se os objetivos dessa ação não puderem ser suficientemente realizados pelos Estados-membros. ${ }^{13} \mathrm{Em}$ decorrência, como alerta CONRADO $^{14}$, tanto a Comissão Europeia quanto o Tribunal Europeu têm reconhecido a preservação dos institutos nacionais de prestação de serviços públicos mesmo quando possam representar uma ameaça a livre concorrência.

Artigo 106. (ex-artigo 86. do TCE)

1. No que respeita às empresas públicas e às empresas a que concedam direitos especiais ou exclusivos, os Estados-Membros não tomarão nem manterão qualquer medida contrária ao disposto nos Tratados, designadamente ao disposto nos artigos 18 e 101 a 109, inclusive.

${ }^{13}$ Artigo 50 TFCE (ex-artigo 5. o TCE)

1. A delimitação das competências da União rege-se pelo princípio da atribuição. O exercício das competências da União rege-se pelos princípios da subsidiariedade e da proporcionalidade.

2. Em virtude do princípio da atribuição, a União acua unicamente dentro dos limites das competências que os Estados-Membros Ihe tenham atribuído nos Tratados para alcançar os objetivos fixados por estes últimos. As competências que não sejam atribuídas à União nos Tratados pertencem aos Estados-Membros.

3. Em virtude do princípio da subsidiariedade, nos domínios que não sejam da sua competência exclusiva, a União intervém apenas se e na medida em que os objetivos da ação considerada não possam ser suficientemente alcançados pelos Estados-Membros, tanto ao nível central como ao nível regional e local, podendo contudo, devido às dimensões ou aos efeitos da ação considerada, ser mais bem alcançados ao nível da União.

As instituições da União aplicam o princípio da subsidiariedade em conformidade com o Protocolo relativo à aplicação dos princípios da subsidiariedade e da proporcionalidade. Os Parlamentos nacionais velam pela observância do princípio da subsidiariedade de acordo com o processo previsto no referido Protocolo.

4. Em virtude do princípio da proporcionalidade, o conteúdo e a forma da ação da União não devem exceder o necessário para alcançar os objetivos dos Tratados.

As instituições da União aplicam o princípio da proporcionalidade em conformidade com o Protocolo relativo à aplicação dos princípios da subsidiariedade e da proporcionalidade.

14 CONRADO, Regis da Silva. Serviços públicos à brasileira: fundamentos jurídicos, definição e aplicação. São Paulo: Saraiva, 2013. p. 116. 
AMARAL, Marcelo Quevedo do. Os serviços de interesse econômico geral (sieg) no direito comunitário europeu. Revista Eletrônica Direito e Política, Programa de Pós-Graduação Stricto Sensu em Ciência Jurídica da UNIVALI, Itajaí, v.10, n.4, $3^{\circ}$ quadrimestre de 2015. Disponível em: www.univali.br/direitoepolitica - ISSN 1980-7791.

2. As empresas encarregadas da gestão de serviços de interesse econômico geral ou que tenham a natureza de monopólio fiscal ficam submetidas ao disposto nos Tratados, designadamente às regras de concorrência, na medida em que a aplicação destas regras não constitua obstáculo ao cumprimento, de direito ou de fato, da missão particular que Ihes foi confiada. O desenvolvimento das trocas comerciais não deve ser afetado de maneira que contrarie os interesses da União.

3. A Comissão velará pela aplicação do disposto no presente artigo e dirigirá aos Estados-Membros, quando necessário, as diretivas ou decisões adequadas.

Temos que considerar também que a noção de empresa pública no Direito Comunitário Europeu é bem abrangente, incluindo todas as empresas, sob quaisquer formas jurídicas, sob as quais o Estado possa execer uma influência dominante sobre sua atuação, decisões e relações econômicas. Segundo CAMPELLO ${ }^{15}$, a adoção de uma noção ampla de empresa pública tem por objetivo impedir que os Estados-membros hajam em relação às empresas sujeitas ao seu controle direto de maneira a frustrar a aplicação das normas de concorrência comunitária. Portanto, o Direito Comunitário considera empresa pública "qualquer empresa sobre a qual os poderes públicos possam exercer direta ou indiretamente uma influência por força de direitos de propriedade, de participação financeira ou das disposições que regem a empresa em causa"

Outra questão importante diz respeito ao âmbito de interpretação e definição que o Direito Comunitário Europeu atribui "a missão particular confiada" as SIEG e a justificativa legitimadora do afastamento das regras de concorrência. Como observa JAEGER JúNIOR ${ }^{16}$, a Comissão definiu serviços de interesse econômico geral como as atividades que são desenvolvidas em favor da coletividade e que estejam vinculadas com o dever do Estado de assegurar o bem-estar.

${ }^{15}$ CAMPELLO, Dyle. O Direito da Concorrência no direito comunitário europeu: uma contribuição ao MERCOSUL. Rio de Janeiro: Renovar, 2001. p. 144.

16 JAEGER JUNIOR, Augusto. Mercado comum e interno e liberdades econômicas fundamentais. p. 466. 
AMARAL, Marcelo Quevedo do. Os serviços de interesse econômico geral (sieg) no direito comunitário europeu. Revista Eletrônica Direito e Política, Programa de Pós-Graduação Stricto Sensu em Ciência Jurídica da UNIVALI, Itajaí, v.10, n.4, $3^{\circ}$ quadrimestre de 2015. Disponível em: www.univali.br/direitoepolitica - ISSN 1980-7791.

Justamente com esse espírito que o Tratado sobre o Funcionamento da União Européia (TFCE) consagra o papel dos serviços de interesse económico geral no conjunto dos valores comuns da União e o papel que desempenham na promoção da coesão social e territorial. Para tanto, permitem que a União e os seus Estados-Membros, dentro do limite das respetivas competências e no âmbito de aplicação dos Tratados, mantenham esses serviços com base em princípios e em condições, nomeadamente econômicas e financeiras, que Ihes permitam cumprir as suas missões ${ }^{17 \prime \prime}$

Normalmente eles são criados pelas autoridades públicas e funcionam sob a sua responsabilidade, ainda que a gestão esteja cedida a um operador público ou privado externo à administração. O conceito aplica-se sobretudo às atividades chamadas de rede. Entre elas estão a distribuição de eletricidade, gás, água, transporte públicos, correios e telecomunicações. ${ }^{18}$

Como destaca $\operatorname{CONRADO}^{19}$, é a importância dada à preservação da qualidade do serviço com o estabelecimento de preço acessível, a preservação do meio ambiente, acesso universal, igualdade, transparência dentre outros princípios buscados pela União Européia que assentam os fundamentos dos Serviços de Interesse Econômico Geral - SIEG.

O protolcolo no 26 da União Európeia expressou claramente esse objetivo ao reafirmar a competência dos Estados-Membros para prestar, mandar

17 Artigo $14^{\circ}$ (ex-artigo 16 do TCE). Sem prejuízo do disposto no artigo 40 do Tratado da União Europeia e nos artigos 93, 106 e 107 do presente Tratado, e atendendo à posição que os serviços de interesse económico geral ocupam no conjunto dos valores comuns da União e ao papel que desempenham na promoção da coesão social e territorial, a União e os seus Estados-Membros, dentro do limite das respetivas competências e no âmbito de aplicação dos Tratados, zelarão por que esses serviços funcionem com base em princípios e em condições, nomeadamente econômicas e financeiras, que lhes permitam cumprir as suas missões. O Parlamento Europeu e o Conselho, por meio de regulamentos adotados de acordo com o processo legislativo ordinário, estabelecem esses princípios e definem essas condições, sem prejuízo da competência dos Estados-Membros para, na observância dos Tratados, prestar, mandar executar e financiar esses serviços.

18 JAEGER JUNIOR, Augusto. Mercado comum e interno e liberdades econômicas fundamentais. p. 466.

19 CONRADO, Regis da Silva. Serviços públicos à brasileira: fundamentos jurídicos, definição e aplicação. p. 105. 
AMARAL, Marcelo Quevedo do. Os serviços de interesse econômico geral (sieg) no direito comunitário europeu. Revista Eletrônica Direito e Política, Programa de Pós-Graduação Stricto Sensu em Ciência Jurídica da UNIVALI, Itajaí, v.10, n.4, $3^{\circ}$ quadrimestre de 2015. Disponível em: www.univali.br/direitoepolitica - ISSN 1980-7791.

executar e organizar serviços de interesse geral não econômicos, destacando:

- o papel essencial e o amplo poder de apreciação das autoridades nacionais, regionais e locais para prestar, mandar executar e organizar serviços de interesse económico geral de uma forma que atenda tanto quanto possível às necessidades dos utilizadores,

- a diversidade dos variados serviços de interesse econômico geral e as diferenças nas necessidades e preferências dos utilizadores que possam resultar das diversas situações geográficas, sociais ou culturais,

- um elevado nível de qualidade, de segurança e de acessibilidade de preços, a igualdade de tratamento e a promoção do acesso universal e dos direitos dos utilizadores.

Também convém observar que, para resolver possíveis dificuldades em identificar os custos de um serviço de interesse econômico geral, o Tribunal de Justiça Europeu tem considerado como critério a mensuração econômica da vantagem indevida, a verificação, a comprovação de vantagem que cause distorção a concorrência. Essa aferição ocorre a partir da determinação da remuneração normal pelos serviços ou produtos em análise. Apreciação que pressupõe uma análise econômica que compreenda todos os fatores envolvidos na atividade produtiva e na sua inserção no mercado. A vantagem, portanto, será oriunda da constatação de que uma empresa recebe um benefício estatal que lhe permite a obtenção de um resultado que não seria obtido em condições normais de mercado, ou seja, o montante da vantagem estatal obtida pela empresa é superior ao custo adicional gerado pelo serviço de interesse econômico geral prestado.

Nesse sentido, os precendentes do Tribunal de Justiça Europeu tem indicado que as subvenções obtidas por empresas que prestam serviço de interesse econômico geral - SIEG - não podem exceder o necessário para cobrir os custos ocasionados pelo cumprimento das obrigações decorrentes dos serviços públicos prestados, sendo que os benefícios devem efetivamente 
AMARAL, Marcelo Quevedo do. Os serviços de interesse econômico geral (sieg) no direito comunitário europeu. Revista Eletrônica Direito e Política, Programa de Pós-Graduação Stricto Sensu em Ciência Jurídica da UNIVALI, Itajaí, v.10, n.4, $3^{\circ}$ quadrimestre de 2015. Disponível em: www.univali.br/direitoepolitica - ISSN 1980-7791.

compensar o funcionamento do serviço público desempenhado, sem prejuízo da possibilidade da empresa ter um lucro razoável, incluindo, portanto, todos os custos ocasionados pela gestão do serviço de interesse econômico geral titulado. Ou seja, a subvenção pública não pode ser utilizada como instrumento de distorção das condições concorrenciais normais do mercado, como um subsídio mascarado, mas pode custear a integralidade dos serviços que aquele Estado entenda ser de interesse econômico geral.

\section{SERVIÇOS DE INTERESSE ECONÔMICO GERAL - SIEG - POSSÍVEIS INFLUÊNCIAS NO SISTEMA BRASILEIRO}

Discutido o papel do sistema de defesa da concorrência dentro do processo de integração da Comunidade Européia, definida e caracterizada a noção de serviço de interesse geral e econômico geral - SIEG - dentro do Direito Comunitário Europeu, necessário se faz uma breve reflexão sobre as possíveis influências desses institutos no sistema jurídico brasileiro.

Assim como o União Europeia, o Brasil possui uma dimensão continental com disparidades sociais e regionais que justificam a adoção de objetivos mais amplos que a pura e simples defesa da liberdade econômica e da concorrência.

Além disso, o liberalismo econômico não pode ser tratado como um dogma, como o estado da arte das ciências econômicas. Muito pelo contrário, o modelo econômico liberal e seus pressupostos são uma corrente ideológica de pensamento dentre muitas outras e como tal deve ser tratado em uma sociedade plural e democrática. BRESSER-PEREIRA, por exemplo, entende que o liberalismo é uma forma equivocada de organizar o capitalismo, destacando que:

$\mathrm{Na}$ verdade, o mercado é apenas uma instituição regulada pelo Estado e, portanto, como o próprio Estado, é uma instituição socialmente construída. 
AMARAL, Marcelo Quevedo do. Os serviços de interesse econômico geral (sieg) no direito comunitário europeu. Revista Eletrônica Direito e Política, Programa de Pós-Graduação Stricto Sensu em Ciência Jurídica da UNIVALI, Itajaí, v.10, n.4, $3^{\circ}$ quadrimestre de 2015. Disponível em: www.univali.br/direitoepolitica - ISSN 1980-7791.

Nesse sentido vale lembrar a proposta de Hegel de ver - Estado que cada sociedade lograr construir como a expressão máxima de sua própria razão - da razão humana historicamente objetivada. ${ }^{20}$

E a Constituição Federal não deixou margem de dúvidas quanto a isso. Ao consagrar expressamente a educação, a saúde, a alimentação, o trabalho, a moradia, o lazer, a segurança, a previdência social, a proteção à maternidade e à infância, a assistência aos desamparados (art.60), além da assistência social e cultura (art. 203) como direitos sociais, a Constituição afirmou um modelo de Estado Social que exige a adoção de medidas administrativas tendentes à estruturação dos serviços essenciais a concretização desses direitos, impondo assim uma postura ativa e interventiva do Estado na execução das ações indispensáveis a efetividade dos compromissos constitucionais.

Nas palavras de BRESSER-PEREIA ${ }^{21}$ a Constituição de 1988 é socialdesenvolvimentista, prevendo a ação do Estado em induzir o desenvolvimento econômico e em garantir os direitos sociais. Nesse sentido GRAU, afirma que a noção de serviço público deve ser construída com vistas a atingir a coesão e a interdependência social, ou seja, as atividades indispensáveis a manutenção da coesão e dos laços de interdependência e solidariedade da sociedade num dado momento histórico.

Também com essa perspectiva deve ser interpretado o papel do Estado brasileiro na atividade econômica, previsto no artigo. $173^{22}$ da Constituição

${ }^{20}$ BRESSER-PEREIRA, Luiz Carlos. A construção política do Brasil. São Paulo: Editora 34, 2015. p. 137.

${ }^{21}$ BRESSER-PEREIRA, Luiz Carlos. A construção política do Brasil. p. 291.

22 Art. 173. Ressalvados os casos previstos nesta Constituição, a exploração direta de atividade econômica pelo Estado só será permitida quando necessária aos imperativos da segurança nacional ou a relevante interesse coletivo, conforme definidos em lei.

$\S 10$ A lei estabelecerá o estatuto jurídico da empresa pública, da sociedade de economia mista e de suas subsidiárias que explorem atividade econômica de produção ou comercialização de bens ou de prestação de serviços, dispondo sobre: (Redação dada pela Emenda Constitucional no 19, de 1998)

I - sua função social e formas de fiscalização pelo Estado e pela sociedade; (Incluído pela Emenda Constitucional no 19, de 1998) 
AMARAL, Marcelo Quevedo do. Os serviços de interesse econômico geral (sieg) no direito comunitário europeu. Revista Eletrônica Direito e Política, Programa de Pós-Graduação Stricto Sensu em Ciência Jurídica da UNIVALI, Itajaí, v.10, n.4, $3^{\circ}$ quadrimestre de 2015. Disponível em: www.univali.br/direitoepolitica - ISSN 1980-7791.

Federal, que permite a atuação direta somente quando necessária aos imperativos da segurança nacional ou a relevante interesse coletivo.

E é, justamente nesse aspecto, muito similar aos objetivos perseguidos pelo processo de unificação Europeu.

Cumpre atentar igualmente para transformações socioeconômicas ocorridas tanto na Europa quanto no Brasil que levaram um número cada vez maior de serviços de natureza pública, antes prestados diretamente pelo Estado, a serem paulatinamente assumidos por empresas privadas. Essa tendência à liberalização econômica verificada na União Europeia no último quartel do século XX influenciou o processo de integração, mas não resultou numa forma absolutamente privatista de gestão pública no Direito Comunitário.

O Direito Comunitário preocupou-se mais em estabelecer regras de proteção a concorrência entre todos os agentes que atuam no mercado, sejam entes públicos ou privados, deixando aos Estados membros estabelecer em quais áreas teriam atuação direta. Assim, novamente se prestigia o princípio da intervenção subsidiária, ou seja, a busca de uma dinâmica de integração pautada pela conciliação e harmonização entre as

II - a sujeição ao regime jurídico próprio das empresas privadas, inclusive quanto aos direitos e obrigações civis, comerciais, trabalhistas e tributários; (Incluído pela Emenda Constitucional no 19, de 1998)

III - licitação e contratação de obras, serviços, compras e alienações, observados os princípios da administração pública; (Incluído pela Emenda Constitucional no 19, de 1998)

IV - a constituição e o funcionamento dos conselhos de administração e fiscal, com a participação de acionistas minoritários; (Incluído pela Emenda Constitucional no 19, de 1998)

$V$ - os mandatos, a avaliação de desempenho e a responsabilidade dos administradores.(Incluído pela Emenda Constitucional n 19, de 1998)

$\S 2^{\circ}$ As empresas públicas e as sociedades de economia mista não poderão gozar de privilégios fiscais não extensivos às do setor privado.

$\S 3^{\circ}$ A lei regulamentará as relações da empresa pública com o Estado e a sociedade.

$\S 4^{\circ}$ A lei reprimirá o abuso do poder econômico que vise à dominação dos mercados, à eliminação da concorrência e ao aumento arbitrário dos lucros.

$\S 50$ A lei, sem prejuízo da responsabilidade individual dos dirigentes da pessoa jurídica, estabelecerá a responsabilidade desta, sujeitando-a às punições compatíveis com sua natureza, nos atos praticados contra a ordem econômica e financeira e contra a economia popular. 
AMARAL, Marcelo Quevedo do. Os serviços de interesse econômico geral (sieg) no direito comunitário europeu. Revista Eletrônica Direito e Política, Programa de Pós-Graduação Stricto Sensu em Ciência Jurídica da UNIVALI, Itajaí, v.10, n.4, $3^{\circ}$ quadrimestre de 2015. Disponível em: www.univali.br/direitoepolitica - ISSN 1980-7791.

tradições e sistemas jurídicos nacionais. Mas, essa opção claramente introduz um elemento de eficiência nas atividades públicas de natureza econômica, sem abrir mão da atuação estatal em áreas consideradas estratégicas para a coletividade.

Observe-se, mais uma vez, que o Direito Comunitário preocupou-se em zelar pela qualidade, universalidade, modicidade tarifária dente outros princípios sensíveis ao seu ordenamento jurídico, reconhecendo a incapacidade histórica de realizar tais objetivos, bem como as enormes distorções resultantes da ação autônoma e desregulada das forças de mercado.

Tais semelhanças com a realidade socioeconômica brasileira, inclusive no que diz respeito com a evolução de muitos dos institutos jurídicos pátrios, permitem que o Direito Comunitário traga ensinamentos que vão além do direito econômico, ao qual o conceito de SIEG inegavelmente pertence. A definição de Comunitária de serviços de interesse geral, que alberga tanto atividades de serviços não econômicos (serviços públicos essenciais como educação, segurança e justiça) quanto os serviços de interesse econômico geral (energia elétrica, transporte, saneamento, telecomunicações, etc.), é de grande valia na criação e interpretação de institutos jurídicos tendentes a concretizar valores constitucionais condizentes com a solidariedade social, o desenvolvimento e a redução das desigualdades ${ }^{23}$.

Da mesma forma, a noção de serviços de interesse econômico geral - SIEG - desmistifica os poderes da absoluta liberdade econômica e da concorrência, estabelecendo hipóteses de afastamento das regras de livre concorrência, permitindo até a atuação monopolista quando conveniente à realização do interesse social.

\footnotetext{
${ }^{23}$ Questões jurídicas resultantes da prestação de serviços públicos por empresas estatais, a exemplo dos serviços postais da Empresa Brasileira de Correios e Telégrafos e a administração de serviços lotéricos pela Caixa Econômica Federal, parecem encontrar na experiência do Direito Comunitário critérios muito mais precisos e adequados as necessidades sociais do que muitas teorias jurídicas adotadas por nossos tribunais superiores para respaldar decisões em ações que envolvem a natureza desses serviços.
} 
AMARAL, Marcelo Quevedo do. Os serviços de interesse econômico geral (sieg) no direito comunitário europeu. Revista Eletrônica Direito e Política, Programa de Pós-Graduação Stricto Sensu em Ciência Jurídica da UNIVALI, Itajaí, v.10, n.4, $3^{\circ}$ quadrimestre de 2015. Disponível em: www.univali.br/direitoepolitica - ISSN 1980-7791.

Isso porque não ocorreu a morte da noção de serviço público mesmo nos países membros da União Europeia. Ao contrário, ela está sendo preservada, na medida em que se preservam os serviços de interesse geral em contexto de intervenção apenas subsidiária da União. Assim, mesmo tendo-se a União Europeia como possível parâmetro econômico ou político, ou seja, como padrão a ser seguido para eventual mudança na Constituição pátria - adotando uma perspectiva mais liberal -, não se pode ignorar a valorização dos SIEG e dos conceitos nacionais afins ao longo do processo de integração. O reconhecimento da importância dos SIEG, inclusive com a aceitação do estabelecimento excepcional de monopólios, ajuda a perceber que, até em um ambiente de grande incentivo à concorrência, a preservação de regimes especiais é legítima e necessária, mesmo em se tratando de atividades econômicas eminentemente privadas. ${ }^{24}$

Outro elemento valioso da experiência Comunitária diz respeito ao critério de mensuração econômica do benefício estatal oferecido ao prestador do serviço de interesse econômico geral considerado aceitável, ou seja, considerado neutro em relação a geração de distorções concorrenciais. 0 Direito Comunitário considera lícito que o Estado ofereça benefícios correspondentes ao custo adicional gerado pela execução do serviço de interesse econômico geral, incluido uma taxa de remuneração (lucro) condizentes.

Ora, tal paradigma, inegavelmente pode ser de grande valia ao Brasil na constituição de novos instrumentos de prestação de políticas públicas. Provavelmente, muitas das notórias carências dos serviços públicos nacionais possam ser superadas ou atenuadas através da atuação de empresas públicas ou privadas subvencionadas pelo Estado para tanto, sem que se possa questionar a legalidade da medida ou o seu caráter anticoncorrencial, a exemplo da experiência desenvolvida pelo Direito Comunitário.

${ }^{24}$ CONRADO, Regis da Silva. Serviços públicos à brasileira: fundamentos jurídicos, definição e aplicação. p. 118 
AMARAL, Marcelo Quevedo do. Os serviços de interesse econômico geral (sieg) no direito comunitário europeu. Revista Eletrônica Direito e Política, Programa de Pós-Graduação Stricto Sensu em Ciência Jurídica da UNIVALI, Itajaí, v.10, n.4, $3^{\circ}$ quadrimestre de 2015. Disponível em: www.univali.br/direitoepolitica - ISSN 1980-7791.

\section{CONSIDERAÇÕES FINAIS}

A experiência desenvolvida pelo Direito Comunitário no processo de integração Europeu temperou as regras de proteção à concorrência com os conceitos de serviço de interesse geral e serviços de interesse econômico geral - SIEG. Esses conceitos constituíram exceções às condutas consideradas anticompetitivas pela comunidade europeia em hipóteses que tiveram por objetivo central assegurar a proteção do interesse geral.

Essa estrutura do Direito Comunitário foi balizada pelo princípio da intervenção subsidiária que estabelece uma dinâmica de integração pautada pela conciliação e harmonização gradual entre as tradições e sistemas jurídicos nacionais. Justamente essa dinâmica permitiu a introdução de mecanismos de defesa da concorrência, ou seja, de um elemento tendente a valorizar a eficiência das atividades públicas de natureza econômica, sem abdicar da atuação estatal em áreas consideradas estratégicas para a coletividade de seus Estados-membros. Busca-se, portanto, compatibilizar o conceito e alcance dos serviços públicos em todo o continente com a formação de um mercado interno unificado e balizado pelo fundamento da livre concorrência. Desse modo, se possibilita uma gradativa convergência das economias, mercados e sistemas jurídicos nacionais, sem abdicar de instrumentos considerados importantes para o desenvolvimento econômico e sustentável, a proteção social, dentre outros objetivos sensíveis a Comunidade Europeia.

A experiência do Direito Comunitário possui preciosos ensinamentos que podem ser assimilados pelo Direito Brasileiro, especialmente quando consideradas as várias similitudes socioeconômicas e de evolução de alguns institutos jurídicos. Nesse sentido, tanto a definição de Comunitária de serviços de interesse geral quanto de serviços de interesse econômico geral podem dar valiosas contribuições, as quais ultrapassam o ramo do direito econômico. Nesse sentido, podem auxiliar na criação de novos instrumentos para prestação de políticas públicas, no aperfeiçoamento do sistema jurídico 
AMARAL, Marcelo Quevedo do. Os serviços de interesse econômico geral (sieg) no direito comunitário europeu. Revista Eletrônica Direito e Política, Programa de Pós-Graduação Stricto Sensu em Ciência Jurídica da UNIVALI, Itajaí, v.10, n.4, $3^{\circ}$ quadrimestre de 2015. Disponível em: www.univali.br/direitoepolitica - ISSN 1980-7791.

existente e, inclusive, na interpretação e resolução de questões controvertidas que envolvem o tema.

Esse aprendizado se faz ainda mais importante para um País como o Brasil, que luta para encontrar instrumentos de prestação de políticas públicas capazes de concretizar valores constitucionais condizentes com a solidariedade social, o desenvolvimento e a redução das desigualdades sociais e regionais.

Mas, necessariamente, esse caminho passa pela reafirmação do caráter social do nosso ordenamento Constitucional e pelo reconhecimento da incapacidade histórica do liberalismo econômico de realizar por si só tais objetivos. A construção de uma sociedade livre, justa e solidária que almeja o desenvolvimento econômico e social, a erradicação da pobreza e a redução das desigualdades, impõe e pressupõe uma cidadania ativa, participativa e consciente do seu papel. Condição incompatível com a simplória dinâmica da confiança cega e incondicionada na ação autônoma e desregulada das forças de mercado, que equipara a noção de cidadania quase a uma relação mercantil, como a solução de todos os males.

\section{REFERÊNCIAS DAS FONTES CITADAS}

BRASIL. Constituição Federal de 1988.

BEZERRA, Helga Maria Sabóia. As transformações da noção de serviço público na União Européia: o serviço de interesse geral do Tratado de Lisboa. Direito, Estado e Sociedade n.32 p. 104 a 133 jan/jun 2008.

BRESSER-PEREIRA, Luiz Carlos. A construção política do Brasil. São Paulo: Editora 34, 2015.

CAMPELLO, Dyle. O Direito da Concorrência no direito comunitário europeu: uma contribuição ao MERCOSUL. Rio de Janeiro: Renovar, 2001. 
AMARAL, Marcelo Quevedo do. Os serviços de interesse econômico geral (sieg) no direito comunitário europeu. Revista Eletrônica Direito e Política, Programa de Pós-Graduação Stricto Sensu em Ciência Jurídica da UNIVALI, Itajaí, v.10, n.4, $3^{\circ}$ quadrimestre de 2015. Disponível em: www.univali.br/direitoepolitica - ISSN 1980-7791.

CONRADO, Regis da Silva. Serviços públicos à brasileira: fundamentos jurídicos, definição e aplicação. São Paulo: Saraiva, 2013.

FAGUNDES, J. Política Industrial e Defesa da Concorrência no Japão. Texto para Discussão: IE/UFRJ, Rio de Janeiro, p.1-43, 1998.

FORGIONI, P. A. Os Fundamentos do Antitruste. São Paulo: Revista dos Tribunais, 2005.

GRAU, E. R. A Ordem Econômica na Constituição de 1988 (interpretação e crítica). 17. ed. São Paulo: Malheiros, 2015.

JAEGER JUNIOR, Augusto. Mercado comum e interno e liberdades econômicas fundamentais. Curitiba: Juruá, 2010.

NUSDEO, A. M. O. Defesa da Concorrência e Globalização Econômica: O Controle da Concentração de Empresas. São Paulo: Malheiros, 2002.

UNIÃO EUROPÉIA. Tratado sobre o Funcionamento da União Européia (TFUE). Jornal Oficial da União Europeia, C326, 26 out. 2012. Disponível em http://eur-lex.europa.eu/collection/eu-law/treatiesforce.html?locale=pt\#new-2-47. Acesso em 27 de jul. 2015.

Tratado da União Européia (TFUE). Jornal Oficial da União Europeia, C326, 26 out. 2012. Disponível em http://eurlex.europa.eu/collection/eu-law/treaties-force.html?locale=pt\#new-2-47. Acesso em 27 de jul. 2015.

Submetido em: Setembro/2015

Aprovado em: Novembro/2015 